\title{
VACUUM ARC MELTING OF PRODUCTION-SIZED URANIUM INGOTS
}

\section{By}

\section{Herbert Davis and Robert I. Schardt}

Facsimile Price $\$$ Microfilm Price $\$$
Available from the
Office of Technical Services
Department of Commerce
Washington 25, D. C.

\section{NATIONAL LEAD COMPANY} OF OHIO

Cincinnati, Ohio 45239

June 8, 1964

\section{$00 N F-603-1$}

reon. 


\section{DISCLAIMER}

Portions of this document may be illegible in electronic image products. Images are produced from the best available original document. 
VACUUM ARC MELTING OF PRODUCTION-SIZED URANIUM INGOTS

By

Herbert Davis and Robert I. Schardt

\begin{abstract}
Consumable-electrode arc melting was used to produce 42 production-sized uranium ingots. Procedures for the arc melting of uranium in a vacuum were established and the effects of the process on metal quality levels were determined.
\end{abstract}

\title{
INTRODUCTION
}

The National Lead Company of Ohio, a prime contractor for the U. S. Atomic Energy Commission, processes uranium concentrates into finished fuel cores of uranium metal. For the past 11 years, tonnage quantities of uranium ingot metal have been produced at this site. The metal is processed through vacuum-induction melting and static casting steps, the resulting ingots are fabricated into fuel cores, and the fuel cores are shipped to AEC reactor sites as feed for plutonium production.

In the continuing effort to Improve product quality, considerable study has been focused on the remelt operation. Here both virgin metal from the reduction of UF 4 and machining residues are remelted by induction in a graphite crucible. The melting, as well as the subsequent casting into graphite ingot molds, takes place in a vacuum. An undesirable characteristic of this operation is that the graphite crucibles and molds contribute carbon to the melt, which forms agglomerated inclusions with the uranium. Thus, the remelt operation is one in which development efforts would yield significant improvements in the quality of the metal product.

In an effort to improve the purity of the uranium ingots, studies have been made of alternate materials for molds and crucibles and of coatings that might be applied to the graphite surfaces to reduce the contamination of the melt. Other factors such as the remelt feed materials or the operating conditions of the vacuum induction furnaces 
are known to affect the ingot quality and were extensively investigated. However, only limited results were obtained. A number of alternate remelt operations were then explored and vacuum arc melting was selected for an engineering and economic evaluation.

Consumable-electrode arc melting is a process that has been used for the purification of such refractory metals as titanium and zirconium; however, the literature reveals no use of the process for the remelting and purification of tonnage quantities of uranium. In this process the metal to be remelted is formed into a long solid cylinder which acts as a consumable negative electrode. A massive copper crucible serves as the positive electrode, as a mold for the molten metal, and as a cooling medium for the ingot. The two electrodes are connected to a d-c power source, and an arc is struck between the consumable electrode and some scraps of the same material in the bottom of the copper crucible. The melting progresses in the evacuated chamber until an ingot of the desired length is achieved.

The initial scoping work on this project was performed offsite at the Battelle Memorial Institute ${ }^{1}$ Encouraged by the results obtained on 4-inch-diameter arc melted ingots cast at BMI, the National Lead Company of Ohio formulated plans for casting 42 production sized ingots for further evaluation. The equipment, procedures, and results of the arc melting test performed at the National Lead Nuclear Metals Division Plant, Albany, New York, are described herein.

\section{DESCRIPTION OF EQUIPMENT}

The consumable-electrode arc melting furnace used (Figure 1) was manufactured by the Lectromelt Corporation, Pittsburgh, Pennsylvania. It was designed for melting refractory and reactive metals under a vacuum or in a controlled atmosphere. The furnace assembly consisted of the following principal components :

1. An electrode drive assembly, equipped with both automatic and manualiy controlled feed systems. The drive system, bus bars, and electrode stem were air-cooled.

2. A crucible assembly (Figure 2), consisting of a massive copper cylinder and base plate. As mentioned in the introduction, this mass of copper provided the only source of ingot cooling. 
3. A vacuum system, consisting of a blower and a roughing pump, along with appropriate valves and gauges for control of inert atmospheres.

4. Furnace instrumentation, consisting of:

a. A thermocouple vacuum-sensing element and meter.

b. A voltmeter, an ammeter, and a watt-hour meter.

c. A multi-point recorder attached to chromelalumel thermocouples for recording the crucible temperatures.

The maximum current capacity of the furnace was 10,000 amperes. The maximum electrode size of 9 inches in diameter and 55 inches long would produce a uranium ingot 11 inches in diameter and 27 inches long.

ELECTRODE PREPARATION

Three sizes of uranium electrodes were formed from vacuum induction melts in uncoated crucibles and cast into MgO wash-coated molds. A summary of the electrode sizes produced appears in Table 1.

\section{TABLE 1}

CONSUMABLE ARC MELTING ELECTRODE SIZES

\begin{tabular}{|c|c|c|c|c|}
\hline \multirow{2}{*}{$\begin{array}{l}\text { Electrode } \\
\text { Diameter } \\
\text { (in.) } \\
\end{array}$} & \multirow{2}{*}{$\begin{array}{c}\text { Electrode } \\
\text { Length } \\
\text { (in.) } \\
\end{array}$} & \multirow{2}{*}{$\begin{array}{c}\text { Electrode } \\
\text { Weight } \\
\text { (1b) }\end{array}$} & \multicolumn{2}{|c|}{$\begin{array}{l}\text { Ingot Size } \\
\text { (in.) }\end{array}$} \\
\hline & & & $\begin{array}{l}\text { Nominal } \\
\text { Diameter }\end{array}$ & $\begin{array}{r}\text { Nominal } \\
\text { Length } \\
\end{array}$ \\
\hline 9 & 40 & 2025 & 11 & 23.5 \\
\hline 8 & 46 & 1800 & 10 & 26.5 \\
\hline 5.5 & 48 & 900 & $7-7-3 / 8$ & 25.0 \\
\hline
\end{tabular}

All of the electrodes (see Figure 3) were grit-blasted with $\mathrm{MgF}_{2}$ slag to remove surface oxidation, and the top of each electrode was machined to provide a groove for attaching the electrode holder or clamping device. 


\section{ARC MELTING PROCEDURE}

The appropriately sized copper crucible was selected, cleaned, and assembled prior to being placed in the furnace shell. A 1-inch thick uranium pad (see Figures 2 and 4 ), previously cast and machined to shape, was placed in the bottom of the crucible. A handful of uranium chips were placed on top of the uranium pad to aid in striking the arc. The electrode was attached to the drive assembly and centered over the opening in the crucible. The furnace was evacuated to 40 microns or less and the arc was struck.

Amperages, voltages, furnace pressures and cruclble temperatures were recorded throughout the duration of the melt. The length of the arc was controlled by means of a servomechanism which, by raising or lowering the electrode, balanced the are voltage against a preset reference voltage. If, on one hand, the reference voltage was set too high, a long arc resulted with excessive arcing toward the sidewall and many sidewall splatters. On the other hand, if the reference voltage was set too low, the electrode would run down into the pool and short the system. The amount of current used could be varied from 0 to 10,000 amperes. Table II lists the pertinent data used for each test phase.

TABLE II - ARC MELTING CONDITIONS

\begin{tabular}{|c|c|c|c|c|c|c|}
\hline & Test Phase & $I$ & II & III & IV & V \\
\hline & Weight (1b) & 3960 & 3960 & 4159 & 1736 & 2060 \\
\hline 锢 & ID (in.) & 11.300 & 11.300 & 10.250 & 7.650 & 7.187 \\
\hline 象 & $O D$ (in.) & 24.5 & 24.5 & 24.5 & 17 & 17 \\
\hline 0 & Height (in.) & 34.25 & 34.25 & 34.5 & 29 & 32 \\
\hline & $\begin{array}{l}\text { Pressure }(\mu) \\
\text { Start. }(\max )\end{array}$ & 40 & 40 & $--*$ & 40 & 40 \\
\hline & Oper. Range & $16-65$ & $27-90$ & $15-170$ & $14-42$ & $10-250$ \\
\hline 웡 & $\begin{array}{l}\text { Current } \\
\text { (kiloamperes) }\end{array}$ & $9.8-10 \cdot 0$ & $9.8-10.0$ & $7 \cdot 9-8.1$ & $5 \cdot 5-5.7$ & $5 \cdot 5-5 \cdot 7$ \\
\hline 崖 & Voltage & $25-27$ & $25-27$ & $24-26$ & $24-26$ & $24-26$ \\
\hline & $\operatorname{Melt.}(\mathrm{Ib} / \mathrm{hr})$ & 2641 & 2831 & 2244 & 1536 & 1587 \\
\hline & Ingot wt. (Ib) & 1599 & 1425 & 1388 & 687 & 678 \\
\hline
\end{tabular}

*At the time this phase was run, no starting pressure was specified. NOTE: The maximum breakout temperature for all phases was $750^{\circ} \mathrm{F}$. 
All runs were made with the electrode, rather than the crucible, attached negatively. A search of the literature had revealed that by designating the electrode as negative, one would obtain a shallow molten pool which would freeze rapidly and allow less time for liquation of the insoluble non-metallic impurities.

Furnace pressure measurements were taken with a thermocouple gauge located in the furnace foreline between the furnace shell and the exhaust valve. Because of this location, the pressure recorded did not necessarily reflect the pressure directly over the melt. However, in all cases, when the arc was struck, the pressure rose rapidly to a maximum value and remained near this value until the arc was extinguished.

Near the completion of the melt, the power was reduced by a predetermined amount at 30 -second intervals until the arc was extinguished. This "hot-topping" procedure was adopted to reduce the formation of voids as the ingot solidified.

After melting was completed, the ingot was cooled in the furnace to $750^{\circ} \mathrm{F}$ (under one-half atmosphere of argon) before removal (see Figure 5).

\section{FURNACE PERFORMANCE}

Production sized uranium ingots of reactor-grade quality were produced by the consumable-electrode arc melting process. Particular attention was given to the stability of the arc and to the evolution of volatiles during the melt. The following observations were made:

1. Slow bubbling was visible on the pool surface. Vigorous splattering of the metal from the electrode tip was also evident.

2. In all ingots, regardless of size, the phenomenon known as "glow discharge" occurred approximately half-way through the melting cycle. A glowdischarge arc is one displaced up the electrode and crucible from its intended position at the electrode tip. This displaced arc does not cause melting but it does heat the crucible wall appreclably. Glow discharge is apparently caused by both the instability of the anode and the positional instability of the cathode ${ }^{2}$. The periods of glow became more frequent and lasted longer as the melt progressed. During these longer periods the metal could be seen to solidify radially in from the walls of the crucible.

3. Generally, the arc remained hard and stable except 
during the periods of glow described above and during the hot-topping period. An examination of the crucible after use showed that during hot topping the unstable arc had etched the cruc1ble wall. This etching had no deleterious effect other than that of producing a rougher ingot surface on the succeeding melt.

The use of massive copper crucibles without the aid of an external cooling media, such as fins, water, etc., is thought to be unique with this furnace installation. Three thermocouples were embedded in the walls of the crucible to measure the efficiency of the copper as a cooling medium. The maximum mold temperature of $850^{\circ} \mathrm{F}$ was recorded during the melting of several 11-inch diameter ingots. At these high temperatures, the copper crucible interface became overheated and alloyed with the uranium ingot. This bond, in turn, made it almost impossible to separate the ingot from the mold. Therefore, without additional cooling, the massive copper crucible could not be used for the larger 11-inch diameter ingots. However, for the lower temperatures encountered in the melting of the smaller ingots (7-, 7-3/8-, and 10-inch sizes), the crucibles proved to be satisfactory.

A difficulty that occurred with crucibles of all sizes was growth of the copper from thermocycling. The inner diameter of the crucibles decreased with each succeeding melt, and it was necessary to rebore the crucible after every fifth melt.

\section{RESULTS AND CONCLUSIONS}

The arc melting of uranium into production sized ingots of reactor-grade quality is feasible, although not readily adaptable to the present production process used at NLO.

The principal advantage of arc melting uranium is the formation of extremely fine carbide (non-metallic) particles and the uniform distribution of these particles throughout the ingot (see Figure 6). It is thought that many of the non-metallic compounds which are too stable to be chemically dissociated by the arc can be physically broken into smaller particles by the arc. It is this type of action in conjunction with the rapid freezing previously described, that is thought to be responsible for the size and dispersement of the inclusions found in the arc-melted ingots.

No contaminants were added to the metal by the arc meiting process. Substitution of the copper crucible for the graphite crucible eliminated a major source of carbon contamination.

Chemical refinement or the elimination of prior electrode 
segregation by the arc melting process was virtually non-existent. The range of the original hydrogen content ( 1.5 to $0.9 \mathrm{ppm}$ ) was reduced by $0.3 \mathrm{ppm}$, but this was no greater than could be expected from any vacuum double-melt operation.

Vertical sections removed from the ingots revealed primary pipe, centerline volds and rimming, which were formed during the solidification of the ingots. Such porosity has been reported to be a frequent result of an unstable arc (glow discharge) ${ }^{3}$. Further experimental work is required in this area.

Fuel cores produced from several arc melted ingots were reactor tested. The results indicated that these cores performed as well as cores currently produced by induction melting.

\section{FUTURE WORK}

A program is required to determine the effects of the following variables on the quality and production rates of ingots:

1. Crucible-to-electrode size ratio.

2. Power input and circuitry.

3. Melting pressures.

4. Control of the solidification pattern. 
${ }^{1}$ H. M. Eikenberry and T. D. Nixon. Consumable Electrode Arc Melting of Uranium, USAEC report NLCO-849, June 15, 1962.

${ }^{2}$ E. W. Johnson, G. T. Hahn and R. Itoh. "Characteristics of Consumable Electrode D. C. Arcs in Argon, Helium and Vacuum," Arcs in Inert Atmospheres and Vacuum, edited by W. E. Kuhn, p. 38. New York: Wiley, 1956.

3W. H. Smith. "The Effect of Variables on the Melting Rate of Metals in the Consumable Electrode Arc Furnace," Arcs in Inert Atmosphere and Vacuum, edited by W. E. Kuhn, p. 49, New York: Wiley, 1956. 


\section{LIST OF FIGURES}

\begin{tabular}{|c|c|}
\hline No. & Title \\
\hline 1 & $\begin{array}{l}\text { Lectro-Melt Consumable-Electrode Arc } \\
\text { Melting Furnace }\end{array}$ \\
\hline 2 & $\begin{array}{l}\text { Copper Crucible for } 7 \text {-inch Diameter } \\
\text { Ingot with Copper Base Plate and } \\
\text { Uranium Starting Pad }\end{array}$ \\
\hline 3 & $\begin{array}{l}\text { Typical Grit-Blasted Electrodes, } 8 \text { Inches } \\
\text { in Diameter }\end{array}$ \\
\hline 4 & Uranium Starting Pad 10 Inches in Diameter \\
\hline 5 & $\begin{array}{l}\text { Typical As-Cast Arc Melted Ingot, } 7 \text { Inches } \\
\text { in Diameter and } 25 \text { Inches Long }\end{array}$ \\
\hline 6 & $\begin{array}{l}\text { Distribution of Non-Metallic Inclusions } \\
\text { (Induction Melted Ingot vs. Arc Melted Ingot) }\end{array}$ \\
\hline
\end{tabular}




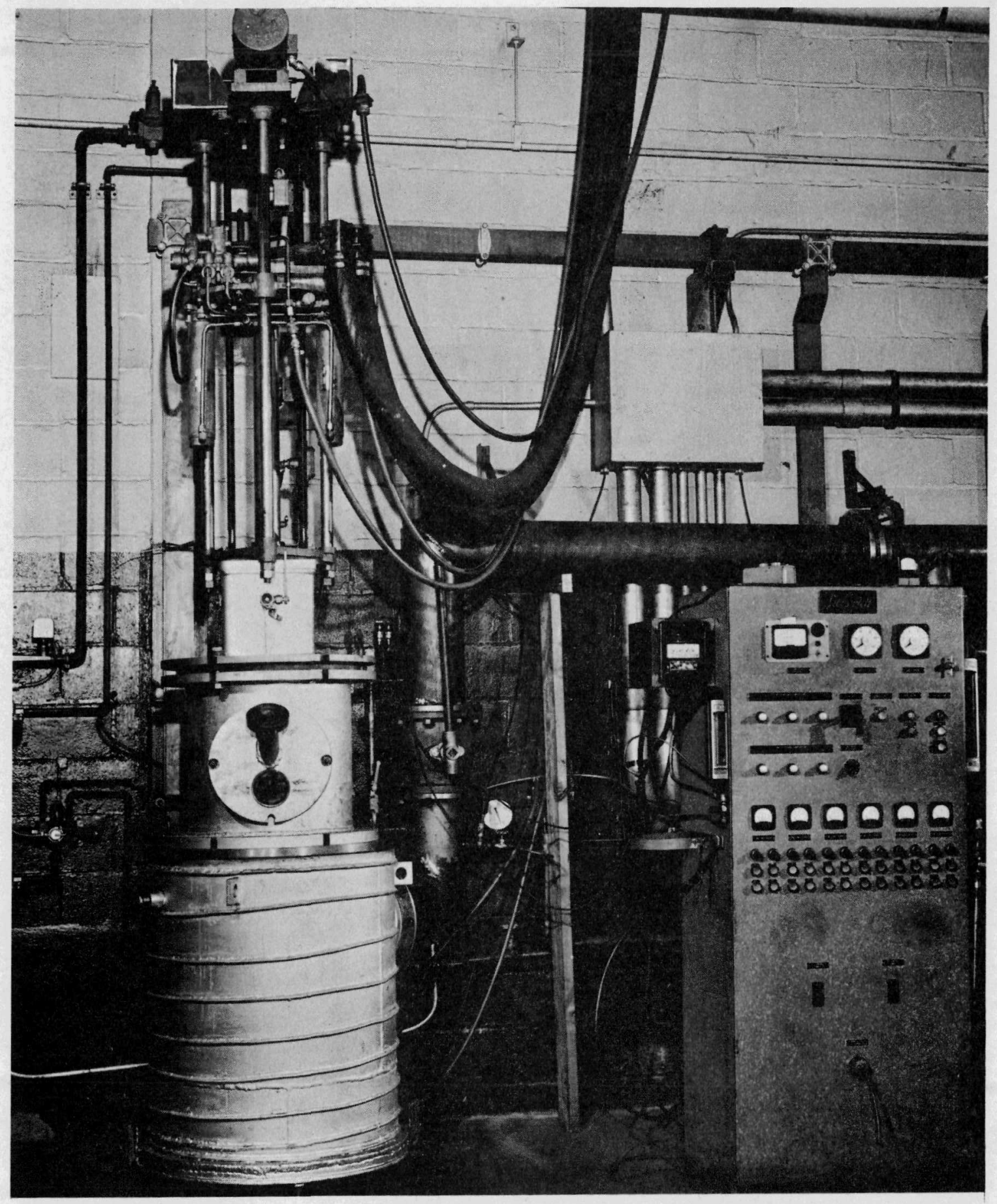

FIGURE 1 Lectromelt Consumable Arc-Melting Furnace 


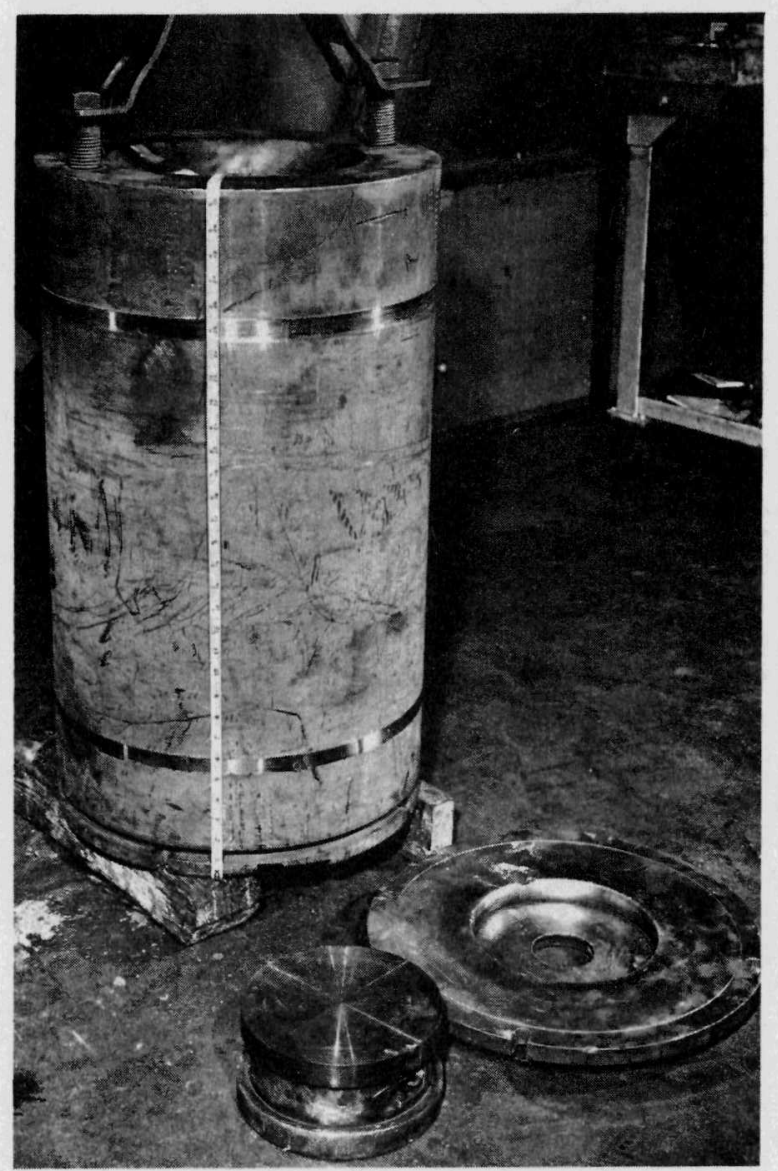

FIGURE 2 Copper Crucible for 7 -Inch Diameter Ingot with Copper Base Plate and Uranium Starting Pad 


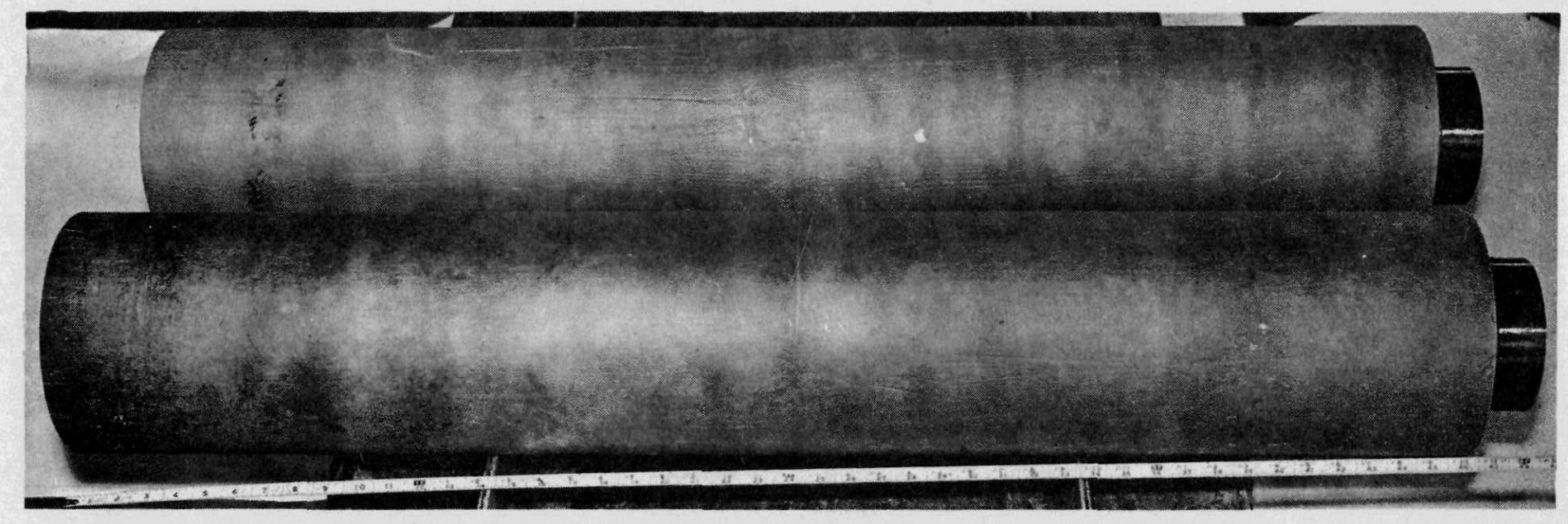

FIGURE 3 Typical Grit-Blasted Electrodes, 8-Inches in Diameter 


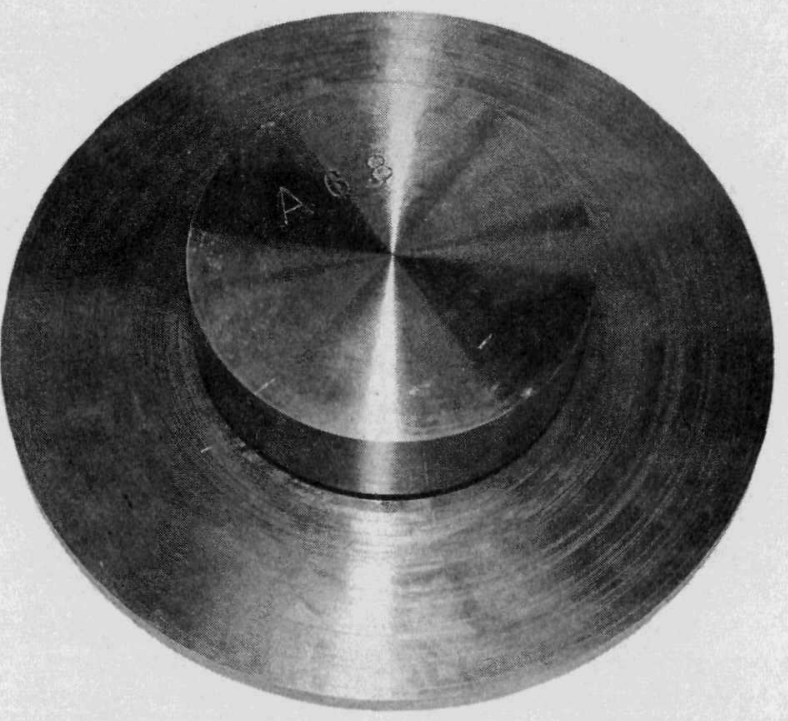

FIGURE 4 Uranium Starting Pad 10 Inches in Diameter 


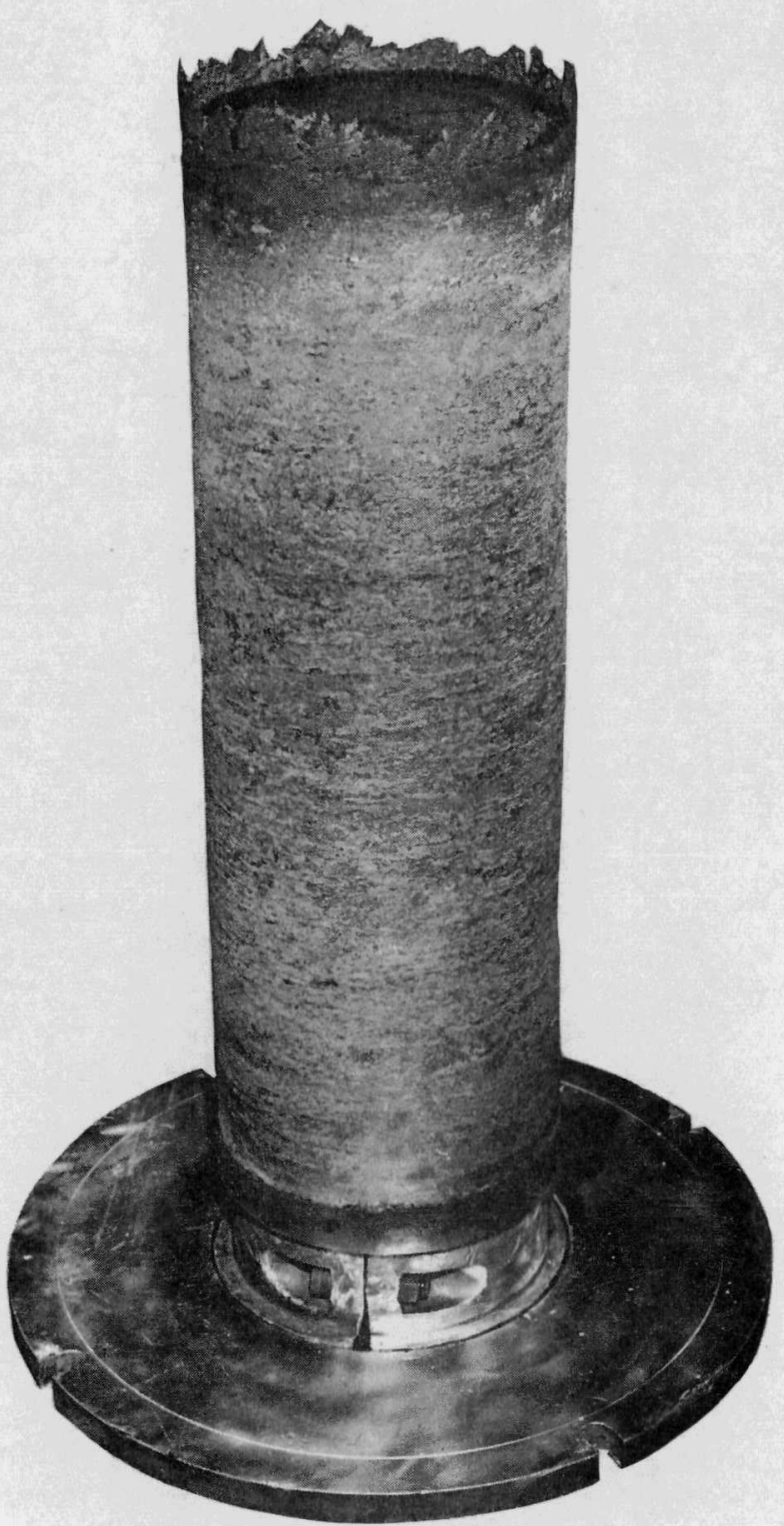

FIGURE 5 Typical As-Cast Arc-Melted Ingot, 7 Inches in Diameter by 25 Inches Long 